\title{
Gene expression profile of stromal cells from potential metastatic sites in breast cancer patients
}

\author{
Paulo R Del Valle ${ }^{1}$, Maria LH Katayama ${ }^{1}$, Dirce M Carraro ${ }^{2}$, Renato Puga ${ }^{2}$, Eduardo C Lyra ${ }^{3}$, Cintia Milani ${ }^{1}$, \\ Patricia B Rozenchan ${ }^{1}$, Maria M Brentani ${ }^{1}$, Maria AAK Folgueira ${ }^{1 *}$
}

From São Paulo Advanced School of Comparative Oncology

Águas de São Pedro, Brazil. 30 September - 6 October 2012

\section{Background}

In breast cancer, there is increasing evidence that stromal cells may influence tumor development in the primary site, as well as in regional and distant metastatic sites. The aim of this study was to compare the expression profile of stromal cells from the primary tumor (PT), lymph nodes metastases $(\mathrm{N}+)$ and bone marrow $(\mathrm{BM})$ from breast cancer patients.

\section{Methods}

Fibroblasts primary culture was established from 11 breast cancer patients. Expression analysis was evaluated in PT $(\mathrm{n}=4), \mathrm{N}+(\mathrm{n}=3)$ and BM $(\mathrm{n}=4)$ through a customized cDNA microarray platform (4,800 ORESTES) analyzed by SAM (TMEV; FDR 0\%) and functional analysis was performed using DAVID. Technical validation was performed in 6 samples and biological validation was performed in fibroblasts obtained from others 25 patients as evaluated by RT-qPCR.

\section{Results}

We observed 267 differentially expressed genes among fibroblasts obtained from the three different sites, which appropriately clustered them in accordance with their origin. Although differences between PT vs. $\mathrm{N}+$ were represented by 20 genes, differences between PT vs. BM and N + vs. BM were more significant (235 and 245 differentially expressed genes respectively). DAVID analysis revealed that these cells differed in many functions including those related to development. Among differentially expressed genes were $\mathrm{NOTCH} 2$ was confirmed less expressed in PT vs. N+ and USP16 confirmed less expressed in PT vs. BM.

\section{Conclusion}

In breast cancer patients, stromal cells obtained from different origins present a differential gene expression profile.

\section{Financial Support}

FAPESP (process number 2009/10088-7) and CAPES.

\section{Author details \\ 'Department of Radiology and Oncology. Faculdade de Medicina da USP São Paulo, Brazil. ${ }^{2}$ Hospital AC Camargo. Fundação Antônio Prudente, AC Camargo, São Paulo, Brazil. ${ }^{3}$ Instituto Brasileiro de Controle do Câncer, IBCC,} São Paulo, Brazil.

Published: 4 April 2013

\section{doi:10.1186/1753-6561-7-S2-P54}

Cite this article as: Del Valle et al.: Gene expression profile of stromal cells from potential metastatic sites in breast cancer patients. BMC Proceedings 2013 7(Suppl 2):P54.

\footnotetext{
* Correspondence: makoike@lim24.fm.usp.br

'Department of Radiology and Oncology. Faculdade de Medicina da USP,

São Paulo, Brazil

Full list of author information is available at the end of the article
} 